\title{
Vulnerabilidade social como critério utilizado na política de assistência estudantil: uma análise conceitual e empírica
}

\author{
Social vulnerability as criteria used in student assistance policy: an analysis of conceptual \\ and empirical
}

\author{
Junia Zacour del Giúdice * \\ Maria das Dores Saraiva Loreto ** \\ Denilson Santos Azevedo ${ }^{* * *}$
}

\begin{abstract}
Resumo:
O critério de vulnerabilidade social é incorporado em diferentes programas para análise das condições de pobreza e exclusão social. Pelo presente estudo, buscou-se examinar de forma conceitual e empírica o critério de vulnerabilidade social adotado na assistência estudantil da Universidade Federal de Viçosa/MG, para a seleção dos estudantes beneficiados, por meio de pesquisa bibliográfica e aplicação de questionário. Relacionou-se a vulnerabilidade social à exclusão social e aos riscos e abordou-se a percepção dos estudantes sobre o tema. Conclui-se que a abordagem empírica se remete à conceitual, estando a vulnerabilidade social concentrada em indicadores econômicos e sociais, representados pela renda, posse de ativos, trabalho, saúde e estrutura familiar.
\end{abstract}

Palavras-chave: Vulnerabilidade social; Assistência estudantil; Ensino Superior.

\begin{abstract}
:
The criterion of social vulnerability is embedded in different programs for the analysis of poverty and social exclusion. For the present study, we sought to examine conceptually and empirically, the criterion of social vulnerability adopted in student assistance from the Federal University of Viçosa / MG for selection of students benefited by means of literature and questionnaire. Related to social vulnerability and social exclusion risks and addressed the students' perception of the subject. We conclude that the empirical approach refers to the conceptual, social vulnerability being concentrated on economic and social indicators, represented by income, ownership of assets, work, health and family structure.
\end{abstract}

\footnotetext{
* Universidade Federal de Viçosa. Graduação e mestrado em Economia Doméstica pela Universidade Federal de Viçosa. Pró-Reitoria de Assuntos Comunitários da Universidade Federal de Viçosa. E-mail: juniazacour@gmail.com

** Universidade Federal de Viçosa. Professor Associado do Departamento de Economia Doméstica da Universidade Federal de Viçosa. Bacharela e Licenciada em Economia Doméstica. Bacharela em Ciências Econômicas. M.S. Economia Rural. E-mail: mdora@ufv.br

*** Universidade Federal de Viçosa. Professor Adjunto IV do Departamento de Educação da Universidade Federal de Viçosa. Bacharel em História e Licenciatura Plena em História, FRJ; Especialização em Metodologia do Ensino Superior, UFF; M.S. História da Educação. E-mail: dazevedo@ufv.br
} 
Keywords: Social vulnerability; Student assistance; Higher education.

\section{Introdução}

As ações que compõem a assistência estudantil da Universidade Federal de Viçosa (UFV), nas áreas de moradia, alimentação, saúde física e mental, esporte e lazer, são direcionadas a todos os estudantes matriculados na Instituição. Porém, existem aquelas que são destinadas exclusivamente ao apoio dos estudantes em situação de vulnerabilidade social, os quais constituíram o público-alvo deste estudo.

Como forma de tornar o acesso à educação superior mais democrático, proporcionando igualdade de oportunidades, as universidades públicas brasileiras vêm adotando diversas políticas de inclusão, considerando que apenas $51,3 \%$ dos jovens, na faixa etária entre 18 e 24 anos, frequentam as universidades (IBGE, 2012). As pesquisas realizadas pelo Fórum Nacional de Pró-Reitores de Assuntos Comunitários e Estudantis (FONAPRACE), sobre o Perfil Socioeconômico e Cultural dos Estudantes de Graduação das IFES, em 2010, constataram que uma parcela significativa dos estudantes (44\%) era oriunda de camadas sociais de baixa renda, ou seja, com renda familiar de até três salários mínimos (FONAPRACE, 2010).

O critério de atendimento a estudantes em vulnerabilidade social é proposto pelo Programa Nacional de Assistência Estudantil (PNAES), instituído pelo Decreto no 7.234, de 19 de julho de 2010, que, no Artigo 5ㅇ, expõe a prioridade de atendimento para estudantes oriundos da rede pública de educação básica ou com renda familiar per capita de até um salário mínimo e meio (BRASIL, 2010). O referido Programa propõe, também, autonomia às instituições para definirem os indicadores a serem utilizados para estabelecer as condições de vulnerabilidade social. Desta forma, torna-se relevante entender o contexto da adoção deste critério para a seleção de estudantes.

Diversos autores, como De León (2006), Carneiro (2005), Cunha et al. (2004), associam a vulnerabilidade social à pobreza, à exclusão social e aos riscos. Entretanto, o tema pobreza é abrangente e multidimensional, estando relacionado com as dimensões econômicas e sociais. A exclusão social, examinada pelo enfoque das situações sociais limites, de pobreza ou marginalidade, demonstra que as pessoas, nessa condição, encontram-se em risco pessoal e social, excluídas das políticas sociais básicas, tais como 
trabalho, educação, moradia, saúde e alimentação. Além disso, a associação entre vulnerabilidade e riscos, sejam eles ligados aos fatores físicos, sociais, econômicos e ambientais, incorpora elementos de exposição e capacidade de enfrentamento dos indivíduos.

Nesse contexto, questionou-se como a UFV, que se empenha em atender aos estudantes em situação de pobreza e segregação socioespacial e econômica, tem incorporado esses indicadores na sua metodologia de avaliação da vulnerabilidade social. E qual foi a percepção dos estudantes sobre a adoção desta metodologia de avaliação e seleção para o recebimento dos benefícios.

O estudo de caso enquadrou-se no tipo descritivo e exploratório, com enfoque metodológico qualitativo e quantitativo, que fez uso tanto da pesquisa documental quanto da aplicação de questionários. O público-alvo constituiu-se de estudantes que recebiam os benefícios e que se formaram no ano de 2012. Participaram da pesquisa 61 estudantes, totalizando $16,8 \%$ da população total.

As variáveis e categorias de análise referiram-se ao conhecimento sobre o funcionamento do Programa de Assistência Estudantil ${ }^{1}$ e suas diretrizes, principalmente quanto aos critérios de seleção ou de vulnerabilidade social, visando identificar as evidências empíricas, que foram contrapostas aos critérios conceituais e com as percepções dos estudantes sobre este tema.

\section{Vulnerabilidade social - Conceitos e interfaces}

Vulnerabilidade, abordada pelo ISDR (International Strategy for Disaster Reduction) e apresentada por De León (2006, p. 13), refere-se ao "conjunto das condições e processos resultantes de fatores físicos, sociais, econômicos e ambientais que aumentam a susceptibilidade da comunidade aos impactos e riscos".

Os fatores físicos englobam a localização e o ambiente, representado por fatores, tais como densidade populacional, situação de um assentamento populacional, entre outros. Os fatores sociais envolvem questões como bem-estar, gênero, saúde, alfabetização, segurança, acesso aos direitos humanos, equidade social, valores tradicionais, crenças e

\footnotetext{
${ }^{1}$ Denomina-se Programa de Assistência Estudantil o conjunto das ações realizado na área de assistência estudantil da UFV.
} 
sistemas organizacionais. Em contraste, os fatores econômicos relacionam-se à pobreza a níveis individual e comunitário, referentes a reservas econômicas, dívida, acesso ao crédito, empréstimos e seguros, entre outros. Finalmente, os fatores ambientais incluem esgotamento e depredação de recursos naturais.

Cientificamente, o termo vulnerabilidade tem sido associado ao meio ambiente, usado em literaturas sobre mudanças climáticas, acidentes e prejuízos causados às comunidades e aos seres humanos, como resultados de pobreza, exclusão e marginalização e sendo generalizado por processos sociais, econômicos e politicos (BARNETT apud BRAUCH, 2005).

Segundo Abramovay et al. (2002), o termo vulnerabilidade social esta comumente relacionado à pobreza, partindo do reconhecimento do fenômeno do bem-estar social e das múltiplas causas e dimensões associadas a esse processo. De acordo com o autor, estudos sobre vulnerabilidade social datam apenas dos últimos anos, período em que se dedicou mais aos estudos sobre pobreza, bem como aos resultados de políticas associadas a eles na América Latina. Tais estudos identificaram os setores mais vulneráveis da população, a serem atendidos pelas políticas sociais, baseando-se apenas no uso de indicadores de renda ou de carências que delimitam a insatisfação de necessidades básicas, em vez de analisar as complexas raízes desse fenômeno.

Carneiro (2005) aborda esta questão considerando que a pobreza pode ser vista por várias dimensões que a definem através dos tempos. A autora apresenta que, antes dos anos 1970, a pobreza era vista como condição exclusivamente econômica, focalizando a renda e o consumo, de indivíduos e famílias, como informação básica tanto para concepção quanto para mensuração. Eram considerados pobres, então, aqueles que não possuem renda suficiente para satisfazer as necessidades básicas de sobrevivência, tais como, saúde, habitação, transporte, educação etc. Nos anos 1970, o conceito de pobreza passa a incorporar variáveis não monetárias que influem na condição de pobreza, por meio do conceito de necessidades básicas. A autora sustenta que são pobres aqueles que não têm suas necessidades básicas satisfeitas, cujo consumo de bens e serviços não atinge o mínimo considerado necessário. Entretanto, esclarece que existe uma relatividade na caracterização e mensuração da pobreza, que as necessidades são relativas aos tempos e lugares e se referem aos padrões vigentes em cada sociedade. 
Nessa perspectiva, de acordo com a mesma autora, o enfoque das capacidades, introduzido nos anos 1980, passa a definir pobreza como carência ou privação de capacidades para os indivíduos operarem no meio social e terem oportunidade de alcançar níveis minimamente aceitáveis de realizações, independente da renda que possuem. Nos anos de 1990, o enfoque da pobreza é ampliado, incorporando a noção de vulnerabilidade, riscos, ativos e empoderamento. A noção de ativos articula-se diretamente com riscos e vulnerabilidade. O mapeamento dos ativos possibilita a identificação de estratégias que indivíduos, famílias e comunidades utilizam, tais como os ativos humanos, físicos, financeiros e sociais, durante períodos de crises e mudanças. As estratégias utilizadas podem produzir resultados diferentes quanto à vulnerabilidade, comprovando que não há uma relação unívoca e unidirecional entre pobreza e vulnerabilidade (CARNEIRO, 2005).

Por outro lado, Cunha et al. (2004) apresentam que a vulnerabilidade esta associada a outros conceitos que têm apoiado a investigação de temáticas, como segregação socioespacial e exclusão social. A abordagem da vulnerabilidade, apesar de se relacionar com o processo de segmentação ou segregação socioespacial, cria novas alternativas na identificação e análise das estratégias utilizadas pela população para mitigar a acumulação de carências urbanas.

Brauch (2005) traz também a concepção de outros pesquisadores sobre o tema, como O'Riordan, Oliver-Smith, Wilches-Chaux e Cardona. Para esses autores, a vulnerabilidade, em nível social, pode ser definida como a incapacidade para evitar o perigo, ou o desconhecimento sobre alguma ameaça iminente, ou mesmo ser forçado a viver em condições de risco. Além disso, a vulnerabilidade esta intrinsecamente ligada a diferentes processos sociais e é originada como consequência de três fatores: fragilidade física ou exposição, ligada à susceptibilidade dos assentamentos humanos serem afetados por fenômenos naturais ou sociais, devido à sua localização em uma área com propensão ao risco; fragilidade socioeconômica, ligada à predisposição em sofrer danos devido à marginalização, segregação social e pobreza; e, finalmente, pela falta de resiliência, relacionada com as limitações de acesso e mobilização de recursos, bem como com a incapacidade de absorção do impacto de uma crise ou desastre, que podem estar ligadas à falta de estratégias de gestão de riscos. Estas dimensões incorporam os custos de 
recuperação e o papel das relações sociais e dos atores em vários níveis, na determinação das condições de exposição ao risco ou perigo.

Nesse sentido, Nathan (2007), caracterizou a vulnerabilidade como um processo complexo abrangendo múltiplas dimensões e que esta em constante mutação, sendo, frequentemente, cumulativo e relacionado ao sujeito e ao risco, causando crises ou agravando-as, ou mesmo adicionando vulnerabilidade a outros riscos, como é o caso dos riscos socioeconômicos, entre outros. Portanto, é preciso especificar qual nível de análise de risco de vulnerabilidade se esta falando, se é individual, do grupo ou da sociedade. A vulnerabilidade é também diferenciada, pois os sujeitos, mesmo estando em níveis semelhantes, têm vulnerabilidades diferentes. Geralmente os mais pobres e excluídos sofrem mais, bem como os menos organizados socialmente. A vulnerabilidade depende do contexto, seja de um indivíduo exposto a riscos naturais, a nível doméstico, ou da comunidade em um nível mais abrangente ou global.

Birkmann ( apud DE LEÓN, 2006, p. 17) associa vulnerabilidade e riscos, incorporando elementos de exposição e capacidade de enfrentamento. $\mathrm{O}$ autor considera que as dimensões de vulnerabilidade são: exposiçao, sensibilidade e adaptação/resiliencia e propõe um modelo que incorpora distúrbios ou crises múltiplas, que emanam das esferas ambiental, social e econômica, sendo as tensões e perturbações manifestadas via estressores. Exemplos de estressores humanos são macroeconomia, política, dinâmicas socioestrutural, globalização etc., e de estressores naturais pode-se citar o estado da biosfera ou mudança ambiental global, entre outros.

O modelo teórico-conceitual, apresentado na Figura 1, envolve a questão da exposição e da capacidade de enfrentamento da vulnerabilidade, em um momento de crise ou perigo, causado por um evento estressor.

A vulnerabilidade refere-se a uma situação de risco, que pode ser ambiental, social ou econômico e para que se opere em sua redução, é necessário atuar, por meio de um sistema de intervenção, nas esferas ambiental, social e econômica, de acordo com o tipo de vulnerabilidade ou risco a que uma pessoa/família ou comunidade esteja exposta. 
Figura 1 - Modelo sobre Exposição e Capacidade de Enfrentamento da Vulnerabilidade

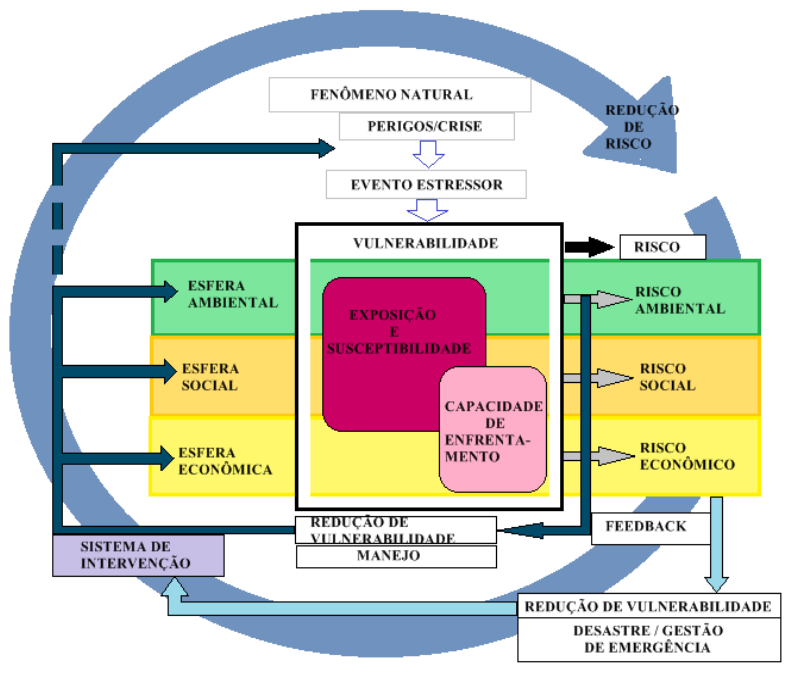

Fonte: Adaptado de Birkmann (apud DE LEÓN, 2006, p. 17).

Quanto maior for a capacidade de o indivíduo prever, lidar, resisitir e se recuperar de uma crise ou desastre, seja ele natural, seja social, menor será sua vulnerabilidade, pois maior será seu poder de conhecimento das causas e, consequentemente, das decisões a serem tomadas para se evitar ou minimizar os riscos e os impactos das crises.

A sensibilidade esta relacionada com as condições existentes e com aspectos do ambiente, enquanto que a resiliência esta associada com a capacidade de enfrentamento dos riscos. A capacidade de enfrentamento é influenciada pela ação, considerando a abordagem teórica, que abrange os meios e formas utilizadas pelas pessoas para agirem, seja por vontade própria, seja como resultado de restrições sociais, governamentais ou econômicas; por modelos de acesso aos bens, de natureza diferente, que permitem a redução da vulnerabilidade; pela crise e teoria do conflito, que se concentra tanto na resolução de conflitos e no controle dos recursos e bens quanto na capacidade de gerenciar situações de crise (DE LEÓN, 2006).

Outra interface da vulnerabilidade social diz respeito à exclusão social, porém o termo exclusão social antecede o de vulnerabilidade, tendo como foco a caracterização de situações sociais limites, de pobreza ou marginalidade, para a realização de intervenções e formulação de políticas públicas voltadas ao enfrentamento dessas questões.

De acordo com Adorno (2001), o termo vulnerabilidade esta relacionado à exclusão econômica e social, considerando-se que um indivíduo ou um grupo torna-se vulnerável 
quando é levado a quebrar seus vínculos sociais com o trabalho, a família ou seu círculo de relações.

O termo pode ser utilizado também para indicar "categorias muito distintas de indivíduos e situações", tais como "inserção precária ou não inserção no mercado", "situações de dependência, segregação, vulnerabilidade de certos grupos" e "situações de desestruturação familiar, doenças e incapacidades ou condições específicas ligadas ao ciclo de vida familiar" (CARNEIRO, 2005 p. 73-74).

A exclusão social conduz, portanto, à vulnerabilidade social, pois se traduz em uma situação de falta de acesso às oportunidades oferecidas pela sociedade aos seus membros, implicando a privação, a falta de recursos ou, de uma forma mais abrangente, a ausência de cidadania, que significa a participação plena na sociedade, nos diferentes níveis em que esta se organiza e se exprime: ambiental, cultural, econômico, político e social.

Nesse contexto, a revisão da literatura sobre a vulnerabilidade revela que o termo tem sido usado em vários contextos diferentes por vários autores, demonstrando que o campo é vasto e que é possível encontrar diferentes noções a respeito de como a vulnerabilidade tem sido percebida. Porém, este estudo aponta para um enfoque da vulnerabilidade voltado à apreensão de fatores que tornam os indivíduos e/ou famílias mais ou menos expostos aos riscos sociais e econômicos, deixando de enfatizar as concepções relacionadas ao meio ambiente, embora não necessariamente as desconsidere. Assim, são as vulnerabilidades de pessoas e, portanto, sociais, que serão o foco deste estudo, pressupondo que a pobreza possua dimensão relacional.

\section{Vulnerabilidade social e sua dimensão empírica}

\section{Critérios Utilizados pelo Programa de Assistência Estudantil da UFV}

Os critérios para a concessão de benefícios aos estudantes foram adaptados ao longo do tempo, acompanhando as políticas adotadas no país. No entanto, a UFV, desde a sua fundação em 1926, tem proporcionado suporte aos estudantes para a permanência na Instituição. No início, o número de vagas acompanhava a demanda e atendiam-se a maioria dos estudantes matriculados, mesmo porque os cursos exigiam dedicação integral. Com o 
processo de expansão da instituição e a demanda sempre crescente pelo apoio à permanência, várias adaptações ou mudanças foram feitas, acompanhando esta demanda. A vulnerabilidade social passou então a ser considerada condição única para o recebimento dos benefícios.

Uma das mudanças realizadas foi com relação à designação da situação do estudante, que antes se utilizava o termo "carente" ou situação de "carência" e que passou a ser caracterizada como vulnerabilidade social. A diferença entre vulnerabilidade e carência, demonstrada por Adorno (2001), esta no uso das palavras usadas para denominar pessoas, que normalmente expressam o lugar ou status que é dado a elas na sociedade. Portanto, dizer que um indivíduo é vulnerável é diferente de dizer que ele é carente. Segundo o referido autor, o termo carente parece rotular a pessoa, como se carência fizesse parte de sua identidade. Quando se chama alguém de carente, que necessita de assistência, não o trata como sujeito portador de direitos, pois esse termo indica alguém desprovido de algo e que, por isso, precisa ser atendido e tratado paternalisticamente. Já o termo vulnerabilidade carrega em si a ideia de compreender, primeiramente, o conjunto de elementos que caracterizam as condições de vida de uma pessoa ou de um grupo, avaliando em que medida tem acesso à rede de serviços disponíveis, como escolas e unidades de saúde; os programas de cultura, lazer e de formação profissional e as ações do Estado que promovem justiça e cidadania entre eles.

O referido autor apresenta também que refletir sobre a vulnerabilidade de uma situação concreta implica pensar em ações positivas e afirmativas que, sem paternalismo nas relações, contribui para a promoção e proteção dos grupos desfavorecidos, reduzindo as desigualdades sociais. Porém, isso somente se consegue com ações que buscam oferecer meios para que possam ampliar o leque de oportunidades de participação social, de acesso aos serviços e ao mercado de trabalho.

Nesse contexto, a avaliação da situação das famílias dos estudantes, candidatos ao recebimento de auxílios, constitui-se, então, da determinação de indicadores de vulnerabilidade social, sendo o principal referente à escassez ou à falta de recursos financeiros e/ou econômicos para custear as despesas de moradia e/ou alimentação. Acredita-se que este é o fator predominante que impede os estudantes de prosseguirem com seus estudos e, de acordo com De León (2006), os fatores econômicos, relacionados à 
pobreza, ao nível individual e comunitário, constituem um dos fatores que indicam a vulnerabilidade.

Pesquisas realizadas pelo Fórum Nacional de Pró-Reitores de Assuntos Comunitários e Estudantis (FONAPRACE), sobre o Perfil Socioeconômico e Cultural dos Estudantes de Graduação das Universidades Federais Brasileiras, em 1998, 2004 e 2010, constataram que uma parcela significativa dos estudantes era oriunda de camadas sociais de baixa renda, ou seja, com renda familiar de até três salários mínimos, sendo que na última pesquisa a representação é de $44 \%$ dos estudantes das federais pertencentes a esta camada social (FONAPRACE, 2010).

O PNAES prevê, em seu Artigo 5ㅇ, o estabelecimento do apoio aos estudantes oriundos da rede pública de educação básica ou com renda familiar per capita de até um salário mínimo e meio, sem prejuízo de demais requisitos fixados pelas instituições federais de ensino superior. E ainda estabelece, no Artigo 3으, parágrafo 2으, que caberá à instituição definir os critérios e a metodologia de seleção dos estudantes a serem beneficiados (BRASIL, 2010).

O processo de avaliação e concessão de benefícios obedece, então, a uma metodologia própria, acompanhando as diretrizes estabelecidas pelo PNAES. A metodologia consiste em avaliação da situação de vulnerabilidade social do estudante e, posteriormente, do processo de seleção e acompanhamento.

Para avaliação da situação de vulnerabilidade social são utilizados meios disponíveis, tais como a aplicação de um questionário socioeconômico e, especialmente, provas documentais, que o estudante apresenta quando faz sua inscrição.

O questionário contempla variáveis relacionadas ao estudante e ao grupo familiar. $\mathrm{Na}$ caracterização da situação do estudante considera-se: o estado civil, a moradia do estudante, que compreende a localização da residência da família; a situação escolar, se a educação básica foi realizada em escola pública ou particular, com ou sem bolsa; a sua situação econômica e de trabalho.

A situação do grupo familiar é avaliada levando-se em consideração as informações gerais obtidas com a documentação que comprova a renda, a composição familiar, a situação civil dos pais, a situação de trabalho e a profissão exercida, a renda familiar, a residência da família (própria, alugada ou financiada), os bens patrimoniais, as despesas e 
problemas de saúde. A renda familiar constitui o somatório de todos os rendimentos das pessoas que compõem o núcleo familiar e rendas obtidas pelos bens imóveis e de capital. As despesas são consideradas apenas como indicadores da situação financeira da família e não são descontadas da renda familiar. Incluem os gastos com aluguel, água, luz, instrução e problemas de saúde.

Os documentos exigidos são as declarações de rendimentos, contracheques de órgãos públicos, declarações de empresas, atestados de autoridades constituídas, comprovantes de despesas, certidões negativas sobre existência de imóveis e veículos. Quando julgado conveniente, informações adicionais são solicitadas aos estudantes, para melhor esclarecer a situação, por meio de entrevistas ou provas documentais complementares.

A análise dos dados, para a definição da situação do estudante, é realizada com base nas informações prestadas no questionário e na documentação apresentada. Mas, nem sempre a documentação é suficiente para esclarecer determinadas situações que são peculiares e que são citadas pelos estudantes no espaço do questionário destinado à justificativa para requererem os benefícios. Nesses casos, são realizadas entrevistas com os estudantes, em que eles têm oportunidade de explicar a situação pela qual sua família vem passando e as estratégias de enfrentamento do problema. Geralmente, são problemas relacionados a alcoolismo dos pais, endividamento ou problemas graves de saúde de algum membro da família.

Após a etapa de análise ou de avaliação, segue-se à de seleção. Inicialmente procedese a uma classificação dos estudantes em três grupos. No primeiro grupo, concentram-se estudantes provenientes de escolas públicas; vindos de cidades que não pertencem à microrregião de Viçosa; cujas famílias não possuem veículos nem outros imóveis, além da moradia. A renda da família é proveniente de apenas um membro, no qual o valor per capita médio é de um terço do salário mínimo vigente ${ }^{2}$. A escolaridade do chefe da família em sua maioria é classificada como "analfabeto" ou "ensino fundamental completo".

No segundo grupo também prevalecem estudantes provenientes de escola pública e de cidades que não pertencem à microrregião de Viçosa. Porém, a maior parte das famílias

\footnotetext{
2 O salário mínimo vigente, na época da entrevista, era no valor de $\mathrm{R} \$ 622,00$ (seiscentos e vinte e dois reais), instituído pelo Decreto № 7.655, de 23 de dezembro 2011, da Presidência da República.
} 
possui veículos e/ou outros imóveis. A situação de trabalho da maioria dos pais é estável e a escolaridade deles prevalece "ensino médio completo". A renda per capita média é de meio salário mínimo.

O terceiro grupo possui perfil socioeconômico semelhante ao anterior, porém a renda per capita média é de $130 \%$ do salário mínimo, representando um valor menor que um salário mínimo e meio.

Os dois primeiros grupos são atendidos prioritariamente com auxílios nas modalidades de moradia, alimentação e manutenção. $O$ terceiro grupo é beneficiado no decorrer do ano, pois o atendimento passa a ser condicionado à existência de vagas (UNIVERSIDADE FEDERAL DE VIÇOSA, 2011).

O acompanhamento é realizado mediante consulta sistemática sobre os indicadores acadêmicos, tais como o rendimento acadêmico dos estudantes e dados sobre evasão, no Sistema Informatizado de Cadastros e Banco de Dados, para verificar possíveis interferências e no sentido de orientar os estudantes na transposição de dificuldades. Além disso, são analisados os relatórios de frequência também gerados pelo mesmo sistema e as prestações de contas feitas pelos estudantes que recebem as bolsas, que consistem na concessão de recurso financeiro (UNIVERSIDADE FEDERAL DE VIÇOSA, 2011).

Nessa perspectiva, os critérios utilizados para avaliação e caracterização da situação de vulnerabilidade social dos estudantes estão coerentes com Warner et al. (2007), quando destacam que: a vulnerabilidade social deve ser considerada um fenômeno multidimensional, sendo um desafio para as pesquisas e ações, sob a perspectiva do sistema social complexo, entender e relativizar a importância dos fatores que contribuem para a vulnerabilidade social. É necessária, portanto, uma abordagem multidisciplinar para enfrentar a complexidade do sistema social e dos padrões de vulnerabilidade.

Quando se toma por base informações sobre as condições de vida das famílias (moradia, profissão, renda, número de dependentes etc.), e não somente informações sobre renda, busca-se o conhecimento de suas realidades e das situações que levam à vulnerabilidade, seja econômica, seja financeira, seja relativa a problemas de saúde etc. Nesse sentido, a vulnerabilidade é dimensionada por indicadores econômicos e sociais, considerando a renda per capita média, a posse de ativos ou bens patrimoniais, condições de trabalho e de saúde dos membros familiares, além da composição e estrutura da família. 


\section{Perfil Familiar dos Usuários do Programa de Assistência Estudantil}

O perfil familiar é um dos indicadores para a delimitação da vulnerabilidade social. Verificou-se que, entre os entrevistados, prevaleceu o estado civil dos pais "casados" (54\%), com idade entre 51 a 60 anos (59\% dos pais e $46 \%$ das mães). Quanto à escolaridade, mais de $60 \%$ dos pais não concluíram o ensino superior, tendo $47 \%$ dos pais e $39 \%$ das mães apenas o ensino fundamental. $O$ tamanho médio da família foi de 5 membros, variando de 02 até 09, o que esta coerente com os dados do Censo 2010 do IBGE, ao revelarem que há 3,39 pessoas vivendo em cada domicílio (IBGE, 2012). Outro dado importante diz respeito à estrutura familiar, considerando o número de famílias cuja situação conjugal dos pais refere-se a "separados" ou "divorciados", representando 26\%. Considera-se que seja um número expressivo, tendo em vista que essa situação pode acentuar as dificuldades financeiras, além de trazer outros prejuízos para a família.

Em relação à situação de trabalho dos pais, considerou-se como trabalho formal o trabalho que é exercido com carteira assinada, de acordo com a legislação trabalhista vigente e, portanto, assegurando ao trabalhador todos os direitos trabalhistas. E o trabalho informal, o trabalho realizado sem carteira assinada, renda fixa e férias pagas. 0 trabalho informal é o tipo de trabalho desvinculado a qualquer empresa, ou seja, é o trabalho indireto em que não há vínculo empregatício por meio de documentação legalizada. No estudo em questão, a maioria dos pais (76\%) possui um trabalho, considerado formal (sendo $38 \%$ dos pais e $38 \%$ das mães).

Analisando a renda familiar, constatou-se que $61 \%$ das famílias tinham renda entre 1 e 3 salários mínimos, oscilando entre a categoria de menos de um salário mínimo (13\%), ou seja, menos de $\mathrm{R} \$ 622,00$ e dez salários mínimos ou mais (2\%). A renda per capita média foi de aproximadamente um salário mínimo, considerando-se que $89 \%$ tinham de 2 a 5 dependentes, ou seja, pessoas morando no mesmo domicílio que dependiam da mesma renda familiar.

As diretrizes do PNAES determinam que o apoio é destinado aos estudantes com renda familiar per capita de até um salário mínimo e meio, o que seria $\mathrm{R} \$ 933,00$. Observase, então, que a população atendida esta dentro da faixa de renda estabelecida. 
Um estudo realizado nos anos 2004 e 2009 pelo Instituto de Pesquisa Econômica Aplicada (IPEA), que analisa a pobreza no Brasil, revela que uma parcela da população, 58\%, vive com menos de um salário mínimo per capita. Em 2009, havia no Brasil cerca de 9 milhões de extremamente pobres ou 4,7\% da população, e os pobres chegavam a quase 18 milhões, 9,4\% dos brasileiros. Portanto, aproximadamente 27 milhões de brasileiros, 14\% da população, viviam com menos de $\mathrm{R} \$ 134,00$ por mês ${ }^{3}$ (OSÓRIO; SOARES; SOUZA, 2011)

Os elevados níveis de pobreza que afligem a sociedade têm como determinante principal a desigualdade na distribuição de renda e das oportunidades de inclusão econômica e social. Essas condições de desigualdade social dificulta a inserção ao ensino superior daqueles jovens oriundos de famílias em estado de pobreza.

\section{Percepção dos Estudantes quanto aos Critérios Adotados pelo Programa de}

\section{Assistência Estudantil}

$\mathrm{Na}$ verificação das percepções dos estudantes quanto ao significado do termo vulnerabilidade social, observou-se que $5 \%$ dos estudantes não souberam defini-la. Os demais participantes se dividiram entre $64 \%$ que ligaram o termo à falta de recursos financeiros ou à pobreza e $28 \%$ que incluíram, além desses, outros fatores. Os estudantes que definiram vulnerabilidade social como falta de recursos financeiros citaram problemas com empregos, dívidas e necessidade de ajuda de terceiros.

A percepção sobre vulnerabilidade remete-se à pobreza, seja pela baixa renda, seja pelo desemprego, que refletem na incapacidade de atender às necessidades básicas. Os estudantes que ligaram o termo a outros fatores incluíram os fatores sociais, emocionais, culturais, e relacionados à saúde, moradia, alimentação e educação.

Quando perguntado se o estudante considera a sua família vulnerável e em que aspectos, $15 \%$ responderam que não, contra $85 \%$ que consideram suas famílias vulneráveis nos aspectos financeiros (64\%), de moradia (21\%), de saúde (8\%), de educação (7\%), de separação dos pais (5\%), de alimentação (3\%), de segurança (3\%) e equidade social e cultural (3\%). A vulnerabilidade foi associada principalmente à questão financeira, tanto

\footnotetext{
3 No estudo em questão, foi considerado o salário mínimo de R\$465,00, vigente em 2009.
} 
em termos de escassez quanto de instabilidade. A insuficiência de renda impõe sacrifícios e renúncias para toda a família, sendo que, à medida que a família encontra dificuldades para cumprir satisfatoriamente suas tarefas básicas de socialização e de amparo aos seus membros, criam-se situações de vulnerabilidade.

Como visto anteriormente, o termo vulnerabilidade social esta comumente relacionado à pobreza. De acordo com Carneiro (2005), as abordagens sobre pobreza partem de distintas formas para a mensuração e alternativas de intervenção, bem como da focalização, para identificar indivíduos e famílias, com implicações nas políticas públicas. As concepções de pobreza se fundamentam em fatores, tais como: insuficiência de recursos financeiros, necessidades básicas insatisfeitas, desqualificação social, vulnerabilidade e riscos.

Com relação aos riscos, foi perguntado aos estudantes se sua família já esteve em situação de risco ambiental, social ou econômico. Quais foram as dificuldades encontradas e quais as estratégias de enfrentamento utilizadas. O risco econômico ou financeiro foi citado por $51 \%$ dos estudantes, seguido dos riscos ambiental (falta de água, enchentes), citado por $8 \%$, além do risco social (condições de moradia, problemas de saúde e alcoolismo, alimentação e outros), destacado por $25 \%$ dos estudantes; $36 \%$ relataram que suas famílias nunca estiveram em situação de risco. Os fatores de risco econômico citados foram desemprego dos pais, do próprio estudante ou de outro membro da família.

Em um dos depoimentos, o estudante era o provedor da família e sua escolha em realizar um curso superior implicou sacrifícios para a mesma. Em tempos difíceis, a família pode atuar como importante rede de suporte, pois as relações familiares e as estratégias das quais as famílias lançam mão em momentos de crise ou mudança, como no caso do desemprego ou separação dos pais, por exemplo, constituem recursos centrais para a redução da vulnerabilidade. Como exemplo citam-se os relatos:

[...] minha mãe saiu de nossa casa, e foi com seus três filhos para casa de minha tia, então minha tia arrumou um barracão para ficarmos, com péssimas condições de moradia. Baixo nível econômico: Depois disso, minha mãe estava desempregada, e passávamos a vida, por doações de amigos e familiares, para nos sustentar. As estratégias utilizadas foram minha mãe conseguir na justiça o direito a pensão alimentícia e termos uma casa. Outra estratégia foi minha mãe estudar e trabalhar para nos sustentar (Entr. n. 15, CCB, sexo feminino, na faixa etária de 18 a 24 anos). 
Minha mãe ao se separar teve que ir morar com minha vó, já que meu pai nunca arcou com nenhuma despesa dos 3 filhos (Entr. n. 19, CCB, sexo feminino, na faixa etária de 18 a 24 anos).

As relações familiares constituem, portanto, um importante ativo e diz respeito à composição, estrutura e coesão dos laços familiares, sendo caracterizadas como redes de apoio para o enfrentamento das situações de vulnerabilidade.

Os fatores de risco social, também citados, relacionam-se a questões de saúde, acesso à escola, conforme depoimento abaixo:

\begin{abstract}
Já estivemos em risco social, e ainda estamos quanto a questões de saúde (pois muitas vezes é necessário uma longa espera para ter acesso a recursos oferecidos pelo SUS), além das dificuldades enfrentadas para que pudéssemos ter acesso a escola, como falta de transporte escolar na época das chuvas. Economicamente, há sempre muita dificuldade em organizar o orçamento, nunca nos faltou nada do que é considerado básico, mesmo porque muitos alimentos são colhidos lá no sítio mesmo, mas sempre estivemos apertados, mas meus pais nunca chegaram a ter grandes dívidas, sempre tomaram muito cuidado com isto" (Entr. 40, CCE, sexo feminino, na faixa etária de 18 a 24 anos).
\end{abstract}

A superação da pobreza pode ser possível, com o fortalecimento de capacidades, mobilização e potencialização de ativos que favoreçam a diminuição de riscos sociais e de vulnerabilidade. Estas estratégias permitem evidenciar a repercussão de pequenas ações que produzem mudanças significativas na vida das pessoas. Assim, conforme destaca Carneiro (2005), o enfoque da vulnerabilidade e riscos contribui para o entendimento da pobreza, orientando para os processos, examinando as estratégias que as famílias utilizam para lidar com os eventos e a queda do bem-estar. Permite, no campo das políticas públicas, direcionar estratégias que devem ser desenvolvidas para o enfrentamento de riscos específicos.

Nessa perspectiva, a vulnerabilidade situa-se "a partir da dimensão de exposição ao risco e da capacidade de resposta, material e simbólica, que indivíduos, famílias e comunidades conseguem fornecer para fazer frente ao risco ou ao choque". "O conceito de risco refere-se a eventos que podem prejudicar o bem-estar das pessoas, que são incertos quanto à magnitude dos danos que podem causar" (CARNEIRO, 2005, p. 97). Todas as pessoas estão sujeitas a riscos diversos, sejam esses naturais, sejam provocados pelos seres 
humanos, sendo que indivíduos e grupos se posicionam diferentemente quanto à capacidade de resposta aos riscos e às mudanças do entorno.

A capacidade de resposta aos riscos das unidades familiares, sejam econômicos, sejam sociais, sejam ambientais, é pouco avaliada pelo programa de Assistência Estudantil da UFV, principalmente pela escassez de recursos humanos.

\section{Conclusões}

Os critérios utilizados para avaliação e caracterização da situação de vulnerabilidade social dos estudantes do Programa de Assistência Estudantil da UFV estão coerentes com o arcabouço teórico aqui apresentado, apesar de se concentrar na questão econômica e social, tendo como indicadores a renda, a posse de bens, o trabalho, a saúde e a estrutura familiar. Emprega-se como critério objetivo a renda das famílias; e subjetivos, as informações sobre a estrutura e as condições de vida das famílias (moradia, profissão, trabalho, renda, número de dependentes, problemas de saúde etc.), buscando-se o conhecimento de suas realidades e das situações que levam à vulnerabilidade social.

O modelo teórico conceitual de vulnerabilidade ressalta que a redução da susceptibilidade e o aumento da capacidade de lidar com os riscos, sejam econômicos, sejam sociais, sejam ambientais, dependem, em muitas situações, das ações de intervenção social, como no caso da assistência estudantil. A intervenção propicia o acesso e a permanência dos estudantes, em situação de pobreza, em um curso superior, os quais terão oportunidades, em um breve futuro, de ingressar em melhores condições no mercado de trabalho, melhorando em consequência a sua qualidade de vida e de suas famílias.

Na percepção dos estudantes, a vulnerabilidade social esta diretamente relacionada à falta de recursos financeiros ou à pobreza e uma minoria incluiu outros fatores, além desses. Os estudantes avaliam suas famílias como vulneráveis, nos aspectos financeiros, de moradia, de saúde, de educação, de separação dos pais, de alimentação, de segurança e equidade social e cultural. Além disso, consideram que suas famílias estão ou já estiveram em situação de risco, principalmente econômico, relacionado ao desemprego dos pais ou de outro membro da família; como as dívidas, empréstimos e separação dos pais, que conduzem a problemas financeiros. 
Diante do exposto, conclui-se que, em nosso país, a continuidade dos estudos em nível superior é ainda limitada para a maior parte dos indivíduos das classes populares, mesmo quando se trata de ingressar em uma instituição pública, em função, preferencialmente, dos riscos econômicos aos quais estão expostas as unidades familiares. As variáveis socioeconômicas incidem não apenas sobre o ingresso, mas também sobre a probabilidade de abandono dos cursos ou evasão. Mas este contexto pode ser alterado com a combinação de medidas de oportunidades de acesso e permanência no ensino superior, combinadas a programas de apoio aos estudantes, caracterizados assistência estudantil.

Porém, as universidades públicas ainda encontram sérias restrições, principalmente orçamentárias, para fazer cumprir seu papel socializador. Os programas oferecidos são, em geral, insuficientes, restritos à oferta de alimentação subsidiada e a poucas vagas em moradias estudantis em vista de uma demanda sempre crescente.

\section{Referências}

ABRAMOVAY, M. et al. Juventude, violência e vulnerabilidade social na América Latina: desafios para políticas públicas. Brasília: UNESCO, BID, 2002.

ADORNO, R. C. F. Um olhar sobre os jovens e sua vulnerabilidade social. São Paulo: AAPCS, 2001.

BRASIL. Decreto no 7.234, de 19 de julho de 2010. Dispõe sobre o Programa Nacional de Assistência Estudantil - PNAES. Brasília, D. F., 19 jul. 2010. Disponível em:

<www.planalto.gov.br>. Acesso em: 02 ago. 2012.

BRAUCH, H. G. Threats, challenges, vulnerabilities and risks in environmental and human security. Bonn: UNU-EHS, 2005. (Publication Series of UNU-EHS, n. 1).

CARNEIRO, C. B. L. Programas de proteção social e superação da pobreza: concepções e estratégias de intervenção. 2005. 332 fls. Dissertação (Doutorado em Ciências Humanas) Faculdade de Filosofia e Ciências Humanas da Universidade Federal de Minas Gerais, Belo Horizonte, 2005.

CUNHA, J. M. P. et al. A vulnerabilidade social no contexto metropolitano: o caso de Campinas. In: ENCONTRO NACIONAL DE ESTUDOS POPULACIONAIS, 14., 2004, Caxambu. Anais... Caxambu: ABEP, 2004. Disponível em:

<http://www.abep.nepo.unicamp.br/site_eventos_abep/PDF/ABEP2004_49.pdf>. Acesso em: 10 dez. 2012.

DE LEÓN, J. C. V. Vulnerability: a conceptual and methodological review. Bonn: UNU-EHS, 2006. (Publication Series of UNU-EHS, n. 4). 
FONAPRACE - FORUM NACIONAL DE PRÓ-REITORES DE ASSUNTOS COMUNITÁRIOS E ESTUDANTIS. II Perfil Socioeconômico e Cultural dos Estudantes de Graduação das Instituições Federais de Ensino Superior. Brasília: FONAPRECE, 2010. Disponível em: <http://www.unb.br/portal/administracao/decanatos/dac/fonaprace/perfil/2004/IFES/fo naprace_com_linhas.pdf>. Acesso em: 28 out. 2012.

IBGE. Censo demográfico 2010: famílias e domicílios - resultados da amostra. Brasília, 2012. Disponível em: <http://www.ibge.gov.br/home/presidencia/noticias/ noticia_impressao.php?id_noticia=2240>. Acesso em: 12 dez. 2012.

NATHAN, F. Natural Disasters, Vulnerability and Human Security. In. BRAUCH, H. G. et al. (Ed.) Facing Global Environmental Change: Environmental, Human, Energy, Food, Health and Water Security Concepts. Berlin: Springer, v. 4, p.1121-1130, 2007.

OSÓRIO, R. G.; SOARES, S. S. D.; SOUZA, P. H. G. F. de. Erradicar a pobreza extrema: um objetivo ao alcance do Brasil. Brasília: IPEA, 2011 (Texto para Discussão n. 1619).

Disponível em

<http://www.ipea.gov.br/agencia/images/stories/PDFs/Tds/td_1619.pdf2011>. Acesso em: 28 out. 2012.

UNIVERSIDADE FEDERAL DE VIÇOSA - UFV. Relatórios anuais. Viçosa, 2011.

WARNER, K. et al. (Ed.) Perspectives on social vulnerability. Bonn: UNU-EHS, 2007. (Publication Series of UNU-EHS, n. 6). 